\title{
Cigarette price and other factors associated with brand choice and brand loyalty in Zambia: findings from the ITC Zambia Survey
}

\author{
Ramzi G Salloum, ${ }^{1}$ Fastone Goma, ${ }^{2}$ Grieve Chelwa, ${ }^{3}$ Xi Cheng, ${ }^{1}$ Richard Zulu, ${ }_{1}^{4}$ \\ Susan C Kaai, ${ }^{5}$ Anne C K Quah, ${ }^{5}$ James F Thrasher, ${ }^{1}$ Geoffrey T Fong ${ }^{5,6,7}$
}

${ }^{1}$ Arnold School of Public Health, University of South Carolina, Columbia, South Carolina, USA

${ }^{2}$ University of Zambia School of Medicine, Lusaka, Zambia ${ }^{3}$ School of Economics, University of Cape Town, Cape Town, Republic of South Africa ${ }^{4}$ Institute of Economic and Social Research, University of Zambia, Lusaka, Zambia ${ }^{5}$ Department of Psychology, University of Waterloo, Waterloo, Ontario, Canada ${ }^{6}$ Ontario Institute for Cancer Research, Toronto, Ontario, Canada

${ }^{7}$ School of Public Health and Health Systems, University of Waterloo, Ontario, Canada

\section{Correspondence to} Dr Ramzi G Salloum, Department of Health Services Policy and Management, Arnold School of Public Health, University of South Carolina, 915 Greene Street, Suite 351, Columbia, SC, 29208, USA; rsalloum@sc.edu

Received 5 July 2014 Accepted 12 January 2015 Published Online First 28 January 2015

\section{CrossMark}

\author{
To cite: Salloum $R G$, \\ Goma F, Chelwa G, et al. \\ Tob Control 2015;24: \\ iii33-iii40.
}

\section{ABSTRACT}

Objectives Little is known about cigarette pricing and brand loyalty in sub-Saharan Africa. This study examines these issues in Zambia, analysing data from the International Tobacco Control (ITC) Zambia Survey. Methods Data from Wave 1 of the ITC Zambia Survey (2012) were analysed for current smokers of factorymade (FM) cigarettes compared with those who smoked both FM and roll-your-own (RYO) cigarettes, using multivariate logistic regression models to identify the predictors of brand loyalty and reasons for brand choice. Results $75 \%$ of FM-only smokers and $64 \%$ of FM+RYO smokers reported having a regular brand. Compared with FM-only smokers, FM+RYO smokers were, on average, older ( $28 \%$ vs $20 \% \geq 40$ years), low income $(64 \%$ vs $43 \%$ ) and had lower education ( $76 \%$ vs $44 \%<$ secondary). Mean price across FM brands was ZMW0.50 (US\$0.08) per stick. Smokers were significantly less likely to be brand loyal ( $>1$ year) if they were aged 15-17 years (vs 40-54 years) and if they had moderate (vs low) income. Brand choice was predicted mostly by friends, taste and brand popularity. Price was more likely to be a reason for brand loyalty among FM+RYO smokers, among $\geq 55$-year-old smokers and among those who reported being more addicted to cigarettes.

Conclusions These results in Zambia document the high levels of brand loyalty in a market where price variation is fairly small across cigarette brands. Future research is needed on longitudinal trends to evaluate the effect of tobacco control policies in Zambia.

Tobacco use-particularly smoking-is the most important preventable cause of premature death and disease, being projected to be responsible for a billion deaths in the 21 st century. ${ }^{1}$ While the tobacco epidemic is levelling off or declining in many high-income countries, tobacco use is on the rise in many low-income and middle-income countries. ${ }^{2}$ Africa is a critically important region where the tobacco epidemic could exert an extraordinary toll. Although sub-Saharan Africa is currently at low levels of tobacco use, projections are that smoking prevalence will increase by almost $39 \%$ by $2030 .^{3-5}$

Zambia, a lower middle-income country, is considered to have relatively moderate cigarette smoking rates, with male prevalence rate estimated at $15.6 \%$ and female prevalence at $0.5 \% .^{5}$ Zambia ratified the WHO Framework Convention on Tobacco Control (FCTC) on 21 August 2008.

Prior to ratifying the FCTC, Zambia had already enacted tobacco control legislation through the
National Public Health Act of 1992. This law required text warning labels on tobacco packaging, banned smoking in a number of public places and banned selling of tobacco products to minors (under 16 years old). ${ }^{6}$ However, these regulations were not well enforced. ${ }^{7}$ In 2008 , the smoking ban was extended to all public places, defined as "any building, premises, conveyance or other place to which the public has access." In 2009, the Ministry of Health took further steps to enhance enforcement of the law by creating punishments ranging from fines of 400 Zambian Kwacha (ZMW)approximately US\$67.00-or higher, to 2 years of imprisonment for smoking in public places. Zambia currently does not ban direct tobacco advertising, promotion and sponsorship.

Research on the prevalence and patterns of tobacco use behaviour in Zambia has been sparse. The Global Youth Tobacco Survey (GYTS) reported that $10.5 \%$ of Zambian students between the ages of 13 and 15 years were current smokers in 2007 (9.3\% among males and $12.1 \%$ among females). ${ }^{6}$ Cigarette consumption in Zambia has been found to be higher among males, urban residents and low educated groups. ${ }^{8}$ Preliminary evidence using established methods to calculate cigarette affordability $^{9} 10$ found that cigarettes in Zambia have become more affordable over the past decade (Chelwa G. The tobacco story in Zambia: a demand, supply, and tax analysis. Unpublished manuscript, University of Cape Town, Cape Town, Republic of South Africa). However, to our knowledge, no prior published studies have reported on price distribution or brand loyalty in Africa.

The vast majority of studies on brand choice comes from the US market, where it has been shown that peer influence and exposure to brand advertising are important factors in brand choice. $^{11} 12$ Smokers with higher income have demonstrated more brand loyalty and older adults have been more brand loyal than smokers under the age of 25 years. ${ }^{13}$ Understanding the factors influencing brand loyalty and the patterns of price distribution are important as countries develop their tobacco control strategies. For instance, taxation may be more effective among younger smokers and those in lower income segments who may be less brand loyal. Also, finding that large price gaps exist between brands may be a direct result of ad valorem taxes, which are not considered to be best practice in tobacco control. ${ }^{14}$

The International Tobacco Control Policy Evaluation Project (ITC Project) is a multicountry 
prospective cohort study designed to measure the impact of key policies of the FCTC. ${ }^{15} 16$ The ITC Zambia Survey is the firstever national study of tobacco use and tobacco control policies in Zambia. Using data from the ITC Zambia Survey, this paper describes cigarette price distribution and purchase patterns, reasons for brand choice and other indicators of brand loyalty among Zambian smokers. We also explore the differences in use and brand loyalty between smokers of only factory-made (FM) cigarettes, and concurrent smokers of FM and hand-rolled or roll-your-own (RYO) cigarettes. We examine whether brand choice and loyalty are associated with price and smoker characteristics in order to inform policymakers of potential tools that can be used to curb the growth of tobacco consumption and prevalence in Zambia.

\section{METHODS}

\section{Sample}

This paper uses cross-sectional data from the ITC Zambia Wave 1 Survey, which provides nationally representative, multidimensional estimates of patterns of tobacco use among the Zambian smoking population. Data on tobacco users and non-users of tobacco were collected using face-to-face interviews, with participants providing their informed consent before starting an interview. Research ethics approval was obtained from the University of Waterloo Human Research Ethics Committee, and from the University of Zambia Biomedical Research Ethics Committee. Data collection was completed through a multistage clustered sampling design between September and December 2012. The ITC Survey took an average of about $60 \mathrm{~min}$ for tobacco users to complete; and about $45 \mathrm{~min}$ for non-users of tobacco to complete. The survey team contacted smokers from 2378 households of a total of 3473 attempted (household contact rate $=68.5 \%$ ). A total of 2273 households responded to the survey (household response rate $=65.4 \%$ ). In any enumerated household all tobacco users up to a maximum of four (randomly selected if necessary) were to be interviewed. Of these, a total of 1588 tobacco users were identified and 1483 tobacco users completed the interview (tobacco user individual response rate $=93.4 \%$ ).

In this paper, only the sample of cigarette smokers is examined (users of smokeless tobacco who did not smoke cigarettes were excluded; $\mathrm{N}=275$ ). A total of 1219 smokers completed the survey. Smokers were defined as those respondents who had smoked at least 100 cigarettes in their lifetime and smoked at least once a week at the time of the survey. Smokers were asked whether they smoke FM cigarettes, RYO cigarettes, or both FM and RYO cigarettes. Because our main focus is on brand loyalty, we excluded smokers of RYO cigarettes who did not also smoke FM cigarettes $(\mathrm{N}=367)$ and those who did not specify cigarette type $(\mathrm{N}=6)$, leaving us with a sample of 846 smokers.

\section{Brand loyalty measures}

All smokers were asked the following questions: "Do you have a brand of cigarettes that you usually smoke?" (coded as 'Yes' vs 'No') and "What is the name of your usual cigarette brand?" The following question was then used to determine whether smokers had had a usual brand for at least a year: "How long have you been smoking your usual brand of cigarettes?" Responses were coded as either $<1$ year or $\geq 1$ year (where we combined two response options: $1-5$ years or $\geq 5$ years).

\section{Reasons for brand choice measures}

Smokers were asked the following question: "In choosing this brand of cigarettes, was part of your decision based on any of the following?" and were given the following response options to choose from: 'the price', 'high quality', 'the taste', 'this brand is less harmful to my health', 'it is a popular brand', 'my friends smoke this brand' and 'the design of the pack'.

\section{Cigarette price and single cigarette purchases}

Respondents were asked to declare the price they paid the last time they purchased cigarettes for themselves. They were asked to report their most recent purchase of cigarettes using any applicable unit of measure (ie, number of loose or single cigarettes; number of cigarette packs and number of cigarettes per pack; and number of cigarette cartons and number of packs/

Table 1 Percentage of FM cigarette smokers reporting same brand (smokers of FM cigarettes only vs FM and RYO)

\begin{tabular}{|c|c|c|}
\hline Total number of smokers $(\mathrm{N}=846)$ & $\begin{array}{l}\mathrm{FM} \text { only } \\
(\mathrm{N}=560)\end{array}$ & $\begin{array}{l}\mathrm{FM}+\mathrm{RYO} \\
(\mathrm{N}=286)\end{array}$ \\
\hline $\begin{array}{l}\text { Total per cent with same brand, } \\
\text { unadjusted }\end{array}$ & 74.9 & 64.1 \\
\hline$\chi^{2}$ & & 11.7 \\
\hline $\mathrm{p}$ Value & & 0.2 \\
\hline \multicolumn{3}{|l|}{ Gender } \\
\hline Male & 91.6 & 95.7 \\
\hline$\chi^{2}$ & & 5.7 \\
\hline p Value & & 0.4 \\
\hline \multicolumn{3}{|l|}{ Age (years) } \\
\hline $15-17$ & 3.7 & 2.1 \\
\hline $18-24$ & 38.0 & 22.8 \\
\hline $25-39$ & 38.5 & 46.7 \\
\hline $40-54$ & 12.4 & 18.3 \\
\hline$\geq 55$ & 7.4 & 10.1 \\
\hline$\chi^{2}$ & & 129.2 \\
\hline $\mathrm{p}$ Value & & $<0.001$ \\
\hline \multicolumn{3}{|l|}{ Income } \\
\hline Low & 43.2 & 63.5 \\
\hline Moderate & 19.1 & 17.2 \\
\hline High & 37.7 & 19.3 \\
\hline$\chi^{2}$ & & 88.0 \\
\hline p Value & & $<0.001$ \\
\hline \multicolumn{3}{|l|}{ Education } \\
\hline Illiterate or < primary & 2.3 & 8.4 \\
\hline Some or completed primary & 41.5 & 67.7 \\
\hline Secondary or higher & 56.2 & 23.9 \\
\hline$\chi^{2}$ & & 269.4 \\
\hline$p$ Value & & $<0.001$ \\
\hline \multicolumn{3}{|l|}{$\mathrm{HSI}$} \\
\hline 0 & 45.7 & 29.6 \\
\hline 1 & 8.6 & 23.7 \\
\hline 2 & 19.7 & 21.3 \\
\hline 3 & 17.3 & 19.7 \\
\hline 4 & 7.6 & 3.9 \\
\hline 5 & 1.2 & 1.4 \\
\hline 6 & 0.0 & 0.3 \\
\hline$\chi^{2}$ & & 98.6 \\
\hline p Value & & $<0.001$ \\
\hline \multicolumn{3}{|l|}{ Purchase type } \\
\hline Single & 84.8 & 77.3 \\
\hline Pack & 15.2 & 22.7 \\
\hline$\chi^{2}$ & & 1.3 \\
\hline$p$ Value & & 0.626 \\
\hline
\end{tabular}

FM, factory-made; HSI, Heaviness of Smoking Index; RYO, roll-your-own. 


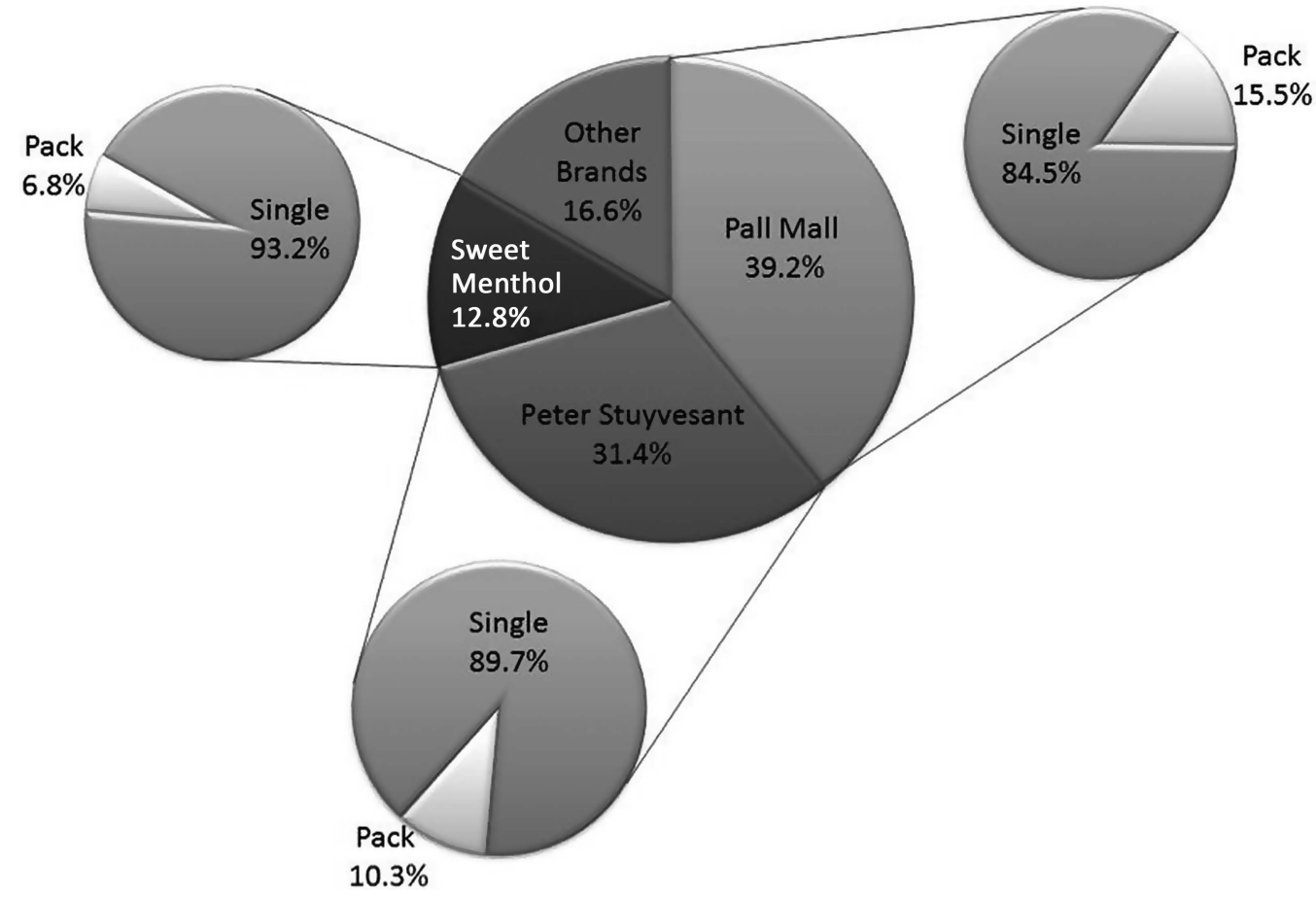

Figure 1 International Tobacco Control (ITC) Zambia Survey Wave 1 (2012): Reported last purchase—regular cigarette brand for factory-made cigarettes and single cigarette versus pack purchases.

cigarettes per carton) for FM cigarettes. Reported FM cigarette prices were then standardised to a price per cigarette stick. We did not analyse reported RYO cigarette prices due to the lack of standard unit prices.

Table 2 Association between individual smoker characteristics and purchase type (single vs pack): OR $(95 \% \mathrm{Cl})$

\begin{tabular}{|c|c|c|}
\hline & \multicolumn{2}{|c|}{ Single cigarette (vs pack) } \\
\hline & FM-only (N=419) & $\mathrm{FM}+\mathrm{RYO}(\mathrm{N}=523)$ \\
\hline \multicolumn{3}{|l|}{ Sex } \\
\hline Male (reference) & - & \\
\hline Female & $0.36(0.13 \text { to } 0.98)^{*}$ & 0.41 (0.16 to 1.04$)$ \\
\hline \multicolumn{3}{|l|}{ Age (years) } \\
\hline 15-17 & $\begin{array}{l}13.46(0.99 \text { to } \\
182.19)\end{array}$ & $\begin{array}{l}18.51(1.37 \text { to } \\
250.15)^{*}\end{array}$ \\
\hline $18-24$ & 1.75 (0.63 to 4.84$)$ & $3.11(1.21 \text { to } 8.03)^{*}$ \\
\hline $25-39$ & 1.18 (0.46 to 3.00$)$ & 1.24 (0.57 to 2.67$)$ \\
\hline 40-54 (reference) & - & - \\
\hline$\geq 55$ & $0.17(0.21 \text { to } 0.89)^{*}$ & 0.45 (0.14 to 1.48 ) \\
\hline \multicolumn{3}{|l|}{ Income } \\
\hline Low (reference) & & - \\
\hline Moderate & 0.88 (0.32 to 2.47$)$ & 1.69 (0.63 to 4.58$)$ \\
\hline High & 1.09 (0.43 to 2.80$)$ & 2.22 (0.91 to 5.44$)$ \\
\hline \multicolumn{3}{|l|}{ Education } \\
\hline $\begin{array}{l}\text { Illiterate or < primary } \\
\text { (reference) }\end{array}$ & - & \\
\hline Some/completed primary & $0.10(0.01 \text { to } 0.87)^{*}$ & 0.72 (0.19 to 2.70$)$ \\
\hline Secondary or higher & $0.07(0.01 \text { to } 0.92)^{*}$ & 0.57 (0.16 to 2.06$)$ \\
\hline \multicolumn{3}{|l|}{ HSI } \\
\hline 0 (reference) & - & - \\
\hline $1-6$ & $0.43(0.21 \text { to } 0.89)^{*}$ & $0.48(0.24 \text { to } 0.95)^{*}$ \\
\hline
\end{tabular}

\section{Other measures}

Sociodemographic measures included in the analysis were sex (male, female), age category (15-17, 18-24, 25-39, 40-54, and 55 years and older); World Bank-defined income category (from monthly household income: low, less than ZMW165 (US\$28); moderate, ZMW165-265 (US\$28-44); high, more than ZMW265 (US\$44)); education level (illiterate or less than primary school, some or completed primary school and secondary school or higher). Level of tobacco dependence was assessed using the Heaviness of Smoking Index (HSI), which was based on the sum of two categorical variables, namely self-reported time to the first cigarette of the day and the number of cigarettes smoked per day (HSI; 7 levels, $0=$ least dependent to $6=$ most dependent). ${ }^{17}$

\section{Analysis}

We used $\chi^{2}$ tests to compare simple bivariate relationships between users of FM cigarettes only and users of FM+RYO cigarettes. The multivariate association between smoker characteristics and type of purchase was examined using logistic regression models. Logistic regressions were also used to test the relationship between smoker characteristics and brand loyalty measures, and the predictors for brand choice. All analyses were weighted to take into account the clustered sampling design. All analyses were conducted using Stata V.13 (StataCorp, College Station, Texas, USA).

\section{RESULTS}

\section{Smoker characteristics}

Of the 846 smokers included in the study, 560 smoked FM-only cigarettes, and 286 smoked both FM and RYO cigarettes (table 1). Reported regular brand use was 74.9\% among FM smokers and $64.1 \%$ among smokers of both FM and RYO cigarettes. The overwhelming majority of smokers were male $(91.6 \%$ for FM vs $95.7 \%$ for FM+RYO). Compared with FM cigarette smokers, 
smokers of both FM and RYO cigarettes were, on average, older (28.4\% vs $19.8 \%$ were 40 years and older), low income $(63.5 \%$ vs $43.2 \%)$ and had lower educational attainment (76.1\% vs $43.8 \%$ $<$ secondary). Smokers of FM-only cigarettes were less addicted than smokers of both FM and RYO cigarettes $(54.3 \%$ vs $70.4 \%$; HSI $>0$ ). More than half of smokers and mixed users stated that their last purchase of cigarettes was of a single cigarette.
Brand distribution and single cigarette purchases

According to smokers who reported smoking a regular brand of FM cigarettes, the Zambian cigarette market is dominated by three brands (figure 1). The most reported regular brand was Pall Mall (39.2\%), followed by Peter Stuyvesant (31.4\%) and Sweet Menthol (12.8\%). Among these smokers, $82.2 \%$ reported buying single cigarettes (vs packs). The prevalence of single cigarette

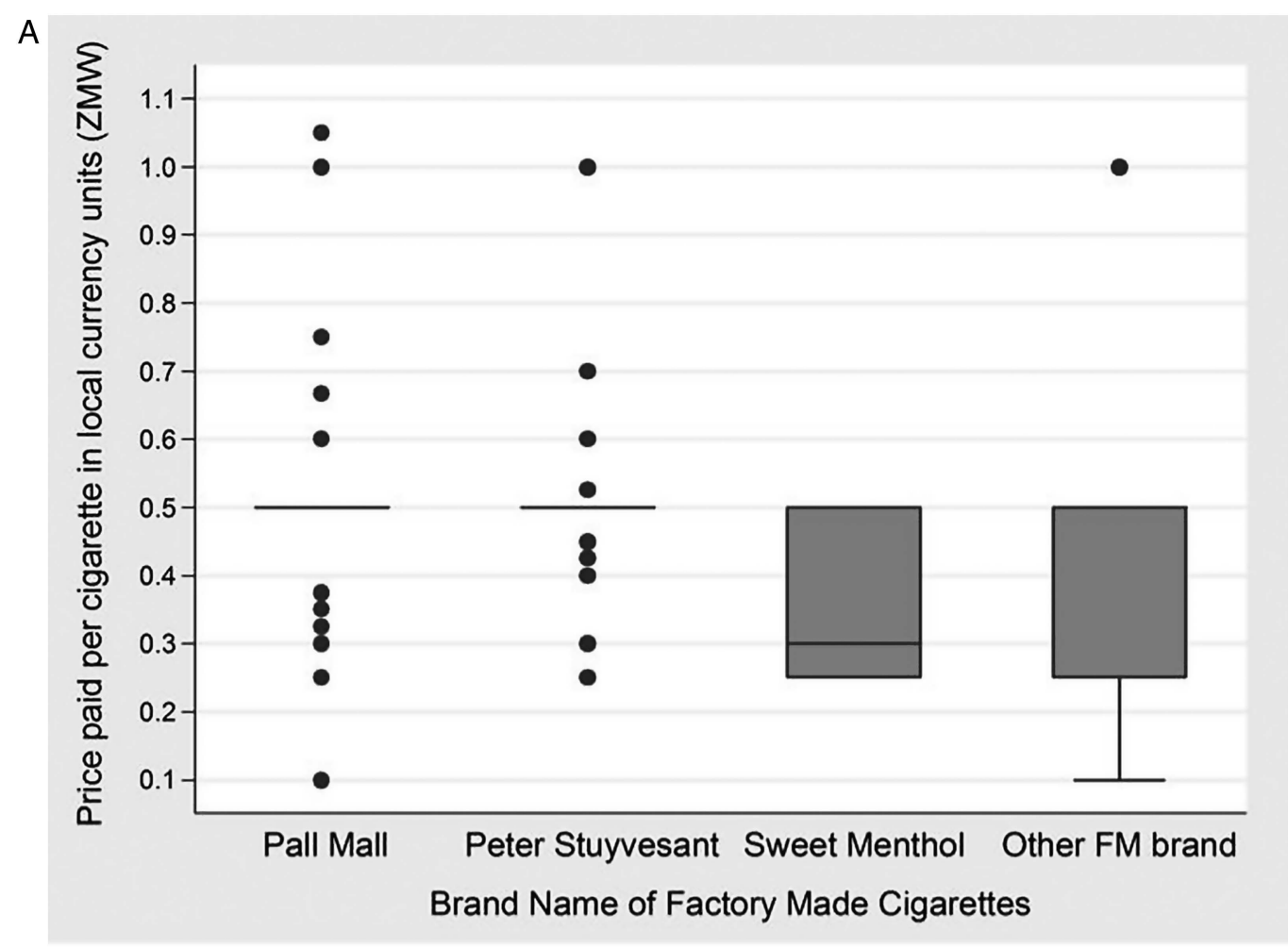

$\mathrm{B}$

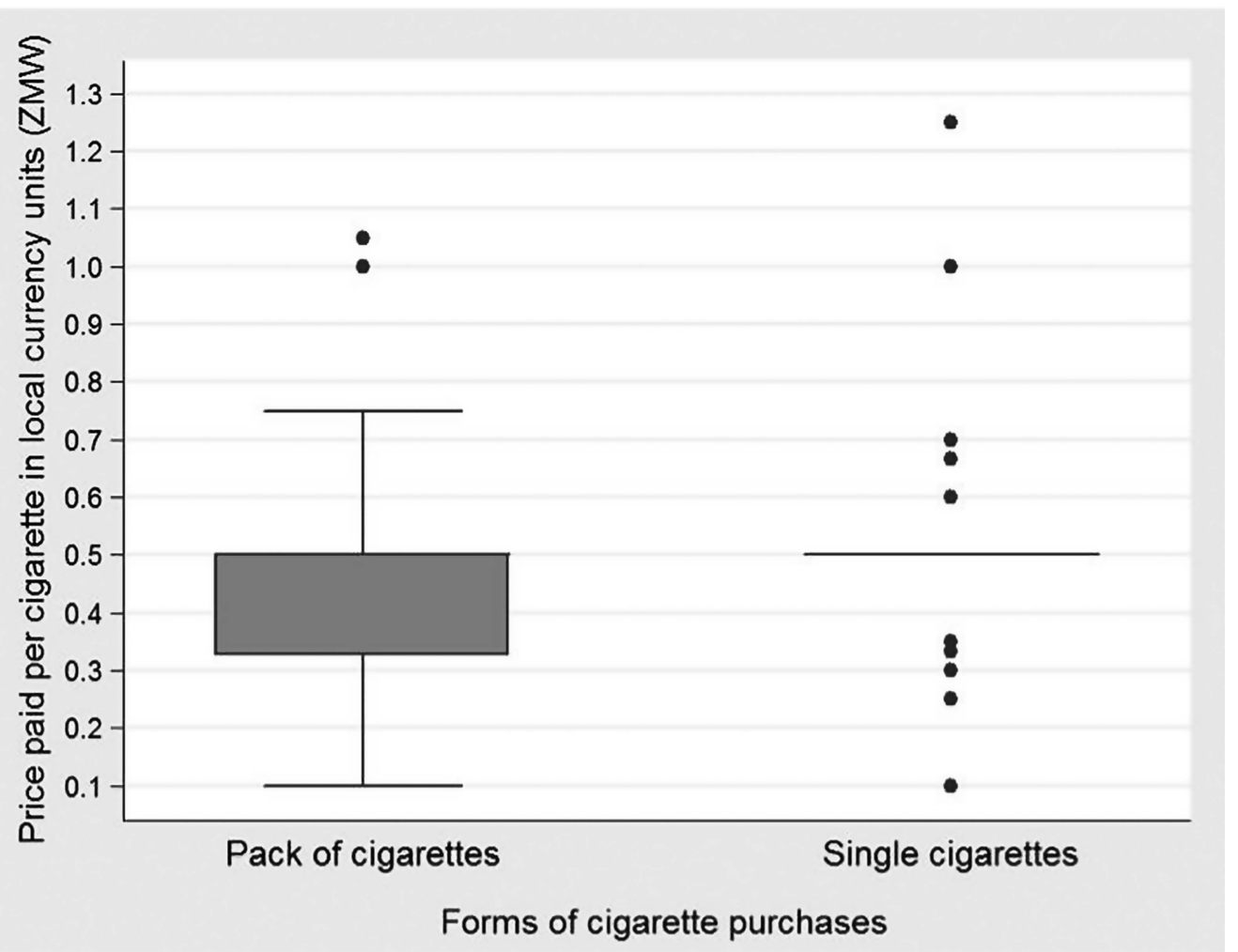

Figure 2 Price per cigarette (in Zambian Kwacha (ZMW)) for factory-made (FM) cigarettes among popular brand varieties (A), and by single cigarette versus pack purchases (B), International Tobacco Control (ITC) Zambia Survey Wave 1 (2012). 
Table 3 Association between individual smoker characteristics and brand loyalty: OR $(95 \% \mathrm{Cl})$

\begin{tabular}{|c|c|c|c|c|}
\hline & \multicolumn{2}{|c|}{ Same brand (any length) } & \multicolumn{2}{|l|}{ Same brand (>1 year) } \\
\hline & FM-only ( $\mathrm{N}=407$ ) & $\mathrm{FM}+\mathrm{RYO}(\mathrm{N}=103)$ & FM-only ( $\mathrm{N}=406)$ & $\mathrm{FM}+\mathrm{RYO}(\mathrm{N}=101)$ \\
\hline \multicolumn{5}{|l|}{ Sex } \\
\hline Male (reference) & - & - & - & \\
\hline Female & 2.00 (0.48 to 8.34$)$ & $3.50(0.17$ to 72.70$)$ & 0.87 (0.31 to 2.49 ) & 6.05 (0.18 to 207.88) \\
\hline \multicolumn{5}{|l|}{ Age (years) } \\
\hline $15-17$ & $0.83(0.23$ to 2.93$)$ & - & $0.32(0.11 \text { to } 0.92)^{*}$ & - \\
\hline $18-24$ & $1.23(0.50$ to 3.03$)$ & $5.70(0.63$ to 51.58$)$ & 0.85 (0.39 to 1.89$)$ & $2.09(0.25$ to 17.32$)$ \\
\hline $25-39$ & 0.85 (0.39 to 1.86$)$ & $1.77(0.46$ to 6.92$)$ & $0.83(0.41$ to 1.70$)$ & $1.22(0.30$ to 5.03$)$ \\
\hline 40-54 (reference) & - & - & - & - \\
\hline$\geq 55$ & $0.56(0.16$ to 1.93$)$ & $2.18(0.15$ to 32.00$)$ & 0.73 (0.22 to 2.44$)$ & 1.87 (0.17 to 20.31$)$ \\
\hline \multicolumn{5}{|l|}{ Income } \\
\hline Low (reference) & - & - & - & - \\
\hline Moderate & $0.78(0.38$ to 1.61$)$ & 6.03 (0.89 to 40.93$)$ & $0.51(0.22 \text { to } 0.68)^{* *}$ & 4.90 (0.73 to 32.90$)$ \\
\hline High & $1.28(0.67$ to 2.43$)$ & $1.59(0.52$ to 4.87$)$ & 0.62 (0.43 to 1.77$)$ & 1.65 (0.48 to 5.69$)$ \\
\hline \multicolumn{5}{|l|}{ Education } \\
\hline Illiterate or < primary (reference) & - & - & - & - \\
\hline Some/completed primary & $0.91(0.42$ to 1.95$)$ & $0.44(0.07$ to 2.79$)$ & 0.43 (0.10 to 2.48$)$ & $0.33(0.04$ to 2.60$)$ \\
\hline Secondary or higher & - & $1.54(0.25$ to 9.42$)$ & 0.53 (0.12 to 3.07 ) & $1.12(0.12$ to 10.16$)$ \\
\hline \multicolumn{5}{|l|}{ Heaviness of Smoking Index } \\
\hline 0 (reference) & - & - & - & - \\
\hline $1-6$ & $0.81(0.44$ to 1.49$)$ & 0.12 (0.33 to 3.74$)$ & 1.55 (0.84 to 2.88$)$ & 2.71 (0.78 to 9.39$)$ \\
\hline \multicolumn{5}{|l|}{ Price } \\
\hline ZMW<0.50 (reference) & - & - & - & - \\
\hline $\mathrm{ZMW}=0.50$ & $0.22(0.10 \text { to } 0.53)^{* * *}$ & 0.45 (0.10 to 2.14$)$ & $0.29(0.11 \text { to } 0.74)^{* *}$ & 0.45 (0.08 to 2.43$)$ \\
\hline $\mathrm{ZMW}>0.50$ & 0.97 (0.08 to 11.02$)$ & $0.41(0.05$ to 3.47$)$ & 1.01 (0.08 to 13.22$)$ & $0.08(0.00$ to 1.15$)$ \\
\hline
\end{tabular}

purchases within each of the top three brands was $84.5 \%$ for Pall Mall, 89.7\% for Peter Stuyvesant and 93.2\% for Sweet Menthol. The associations between smoker characteristics and purchase type (ie, single cigarette vs pack) are shown in table 2. Among FM cigarette only smokers, females and smokers aged $\geq 55$ years were less likely to purchase single cigarettes $(\mathrm{OR}=0.36$ and 0.17 , respectively). Also, those with at least some primary education were significantly less likely to purchase single cigarettes compared with those with less than primary education $(\mathrm{OR}=0.10)$. Finally, smokers with a higher than zero HSI were less likely to choose single cigarettes compared with those with an $\mathrm{HSI}=0(\mathrm{OR}=0.43)$.

\section{Price distribution}

Figure 2A shows the reported median price per cigarette by brand of FM cigarettes. For the two most popular FM brands (ie, Pall Mall and Peter Stuyvesant), the median price per cigarette was ZMW0.50/US\$0.08. The mean prices for both brands coincided with the median: Pall Mall, ZMW0.49 (0.01) mean (SD) and Peter Stuyvesant, ZMW0.50 (0.01). The reported price per cigarette for Sweet Menthol, the third most popular brand, was approximately half of the price of the top two brands. The median price per cigarette for Sweet Menthol was ZMW0.30, with a mean of ZMW0.36 (0.02). Finally, the reported median price per cigarette for all other brands combined was also ZMW0.50, with a mean of ZMW0.40 (0.03). The median price per cigarette for singles is slightly higher than that for pack purchases (ZMW0.48 vs ZMW0.44; figure 2B).

\section{Smoker characteristics and brand loyalty}

The associations between smoker characteristics and brand loyalty are shown in table 3. Among smokers who did not use RYO cigarettes, those with moderate income compared with those with low income $(\mathrm{OR}=0.51)$ and those who paid $\mathrm{ZMW} 0.50$ per cigarette compared with those who paid less $(\mathrm{OR}=0.29)$ were significantly less likely to be loyal to any brand for more than 1 year.

\section{Reasons for brand choice}

Factors predicting the proportion of smokers that nominated reasons for brand choice are shown in table 4. We did not find differences by sex. Smokers between the ages of 15 and 17 years were significantly less likely to choose a brand because of taste compared with older smokers $(\mathrm{OR}=0.07)$. Smokers over the age of 54 years were more likely to choose a brand because of price $(\mathrm{OR}=8.99)$ and popularity $(\mathrm{OR}=3.53)$, compared with those between the ages of 40 and 54 years. Smokers in the high-income group were less likely to choose a brand because of price $(\mathrm{OR}=0.46)$, but more likely to choose their brand because of taste $(\mathrm{OR}=2.99)$, perceived relative harm $(\mathrm{OR}=2.83)$, popularity $(\mathrm{OR}=3.08)$ and friends' advice $(\mathrm{OR}=3.05)$. Compared with the smokers who smoked FM cigarettes exclusively, smokers of both FM and RYO cigarettes were more likely to choose their brand because of price $(\mathrm{OR}=4.59)$, and less likely to choose their brand because of perceived quality $(\mathrm{OR}=0.36)$ and taste $(\mathrm{OR}=0.39)$. Smokers with a non-zero HSI were more likely to choose a brand because of perceived relative harm $(\mathrm{OR}=2.07)$ and popularity $(\mathrm{OR}=1.88)$ relative to smokers with $\mathrm{HSI}=0$. Finally, choosing a brand because of pack design was not significantly associated with any smoker characteristics.

\section{DISCUSSION}

Almost half the smokers surveyed in the ITC Zambia Wave 1 Survey used FM-only cigarettes, with the rest using either RYO 
Table 4 Factors predicting proportion of smokers nominating reasons for brand choice: OR $(95 \% \mathrm{Cl})$

\begin{tabular}{|c|c|c|c|c|c|c|c|}
\hline & Price $(\mathrm{N}=448)$ & Quality (N=451) & Taste $(\mathrm{N}=452$ ) & Health $(\mathrm{N}=423)$ & Popularity $(\mathrm{N}=445)$ & Friends' advice $(\mathrm{N}=444)$ & Pack design $(\mathrm{N}=424)$ \\
\hline \multicolumn{8}{|l|}{ Sex } \\
\hline Male (reference) & - & - & - & - & - & - & - \\
\hline Female & $1.88(0.73$ to 4.85$)$ & $1.59(0.58$ to 4.40$)$ & 1.92 (0.68 to 5.47$)$ & 0.34 (0.05 to 2.06$)$ & 1.64 (0.36 to 7.37$)$ & 0.84 (0.30 to 2.38 ) & $2.98(0.65$ to 13.64$)$ \\
\hline \multicolumn{8}{|l|}{ Age (years) } \\
\hline 15-17 & 0.98 (0.13 to 7.54$)$ & 0.36 (0.07 to 1.75$)$ & $0.07(0.01 \text { to } 0.57)^{*}$ & - & 1.08 (0.18 to 6.38$)$ & $1.66(0.40$ to 6.90$)$ & - \\
\hline $18-24$ & 1.19 (0.46 to 3.08$)$ & 1.91 (0.93 to 3.91$)$ & 0.91 (0.38 to 2.18 ) & 0.74 (0.30 to 1.83 ) & 1.65 (0.80 to 3.42$)$ & 1.89 (0.68 to 5.20$)$ & 0.77 (0.19 to 3.17 ) \\
\hline $25-39$ & $0.99(0.54$ to 1.83$)$ & $1.10(0.57$ to 2.09$)$ & $0.81(0.45$ to 1.45$)$ & 0.85 (0.32 to 2.23$)$ & 1.49 (0.87 to 2.54$)$ & 1.60 (0.69 to 3.73$)$ & 1.84 (0.56 to 6.05$)$ \\
\hline 40-54 (reference) & - & - & - & - & - & - & - \\
\hline$\geq 55$ & $8.99(2.11 \text { to } 38.39)^{* *}$ & 1.13 (0.33 to 3.85$)$ & $0.60(0.22$ to 1.66$)$ & 0.68 (0.20 to 2.32$)$ & $3.53(1.41 \text { to } 8.82)^{* *}$ & $0.46(0.15$ to 1.37$)$ & 0.07 (0.00 to 1.59$)$ \\
\hline \multicolumn{8}{|l|}{ Income } \\
\hline Low (reference) & - & - & - & - & - & - & - \\
\hline Moderate & $1.65(0.74$ to 3.65$)$ & 0.63 (0.36 to 1.10$)$ & $0.78(0.38$ to 1.59$)$ & $1.80(0.80$ to 4.06$)$ & $1.63(0.82$ to 3.23$)$ & $2.91(1.48 \text { to } 5.70)^{* *}$ & 1.09 (0.26 to 4.58$)$ \\
\hline High & $0.46(0.21 \text { to } 0.99)^{*}$ & 1.41 (0.84 to 2.38$)$ & $2.99(1.60 \text { to } 5.59)^{* * *}$ & $2.83(1.24 \text { to } 6.45)^{*}$ & $3.08(1.67 \text { to } 5.65)^{* * *}$ & $3.05(1.65 \text { to } 5.64)^{* * *}$ & $1.33(0.28$ to 6.25$)$ \\
\hline \multicolumn{8}{|l|}{ Education } \\
\hline Illiterate or < primary (reference) & - & - & - & - & - & - & - \\
\hline Some/completed primary & 0.61 (0.16 to 2.39$)$ & $0.86(0.27$ to 2.80$)$ & $1.05(0.35$ to 3.16$)$ & $0.86(0.14$ to 5.43$)$ & 0.53 (0.18 to 1.59$)$ & 0.72 (0.20 to 2.64$)$ & $2.04(0.21$ to 19.53$)$ \\
\hline Secondary or higher & $0.46(0.11$ to 1.95$)$ & $1.06(0.32$ to 3.58$)$ & $1.66(0.51$ to 5.39$)$ & $0.36(0.06$ to 2.22$)$ & $0.40(0.13$ to 1.17$)$ & $0.38(0.11$ to 1.35$)$ & $4.32(0.33$ to 56.98$)$ \\
\hline \multicolumn{8}{|l|}{ Concurrent use of HR/RYO } \\
\hline FM-only (reference) & - & - & - & - & - & - & - \\
\hline $\mathrm{FM}+\mathrm{RYO}$ & $4.59(1.81 \text { to } 11.66)^{* *}$ & $0.36(0.18 \text { to } 0.72)^{* *}$ & $0.39(0.18 \text { to } 0.86)^{*}$ & 0.45 (0.19 to 1.03$)$ & $1.82(0.93$ to 3.56$)$ & $2.23(0.96$ to 5.19$)$ & 0.71 (0.23 to 2.14$)$ \\
\hline \multicolumn{8}{|l|}{ Heaviness of Smoking Index } \\
\hline 0 (reference) & - & - & - & - & - & - & - \\
\hline $1-6$ & $1.76(0.86$ to 3.61$)$ & $1.39(0.81$ to 2.40$)$ & 0.89 (0.45 to 1.74$)$ & $2.07(1.03 \text { to } 4.13)^{*}$ & $1.88(1.09 \text { to } 3.25)^{*}$ & $1.18(0.67$ to 2.10$)$ & $1.84(0.57$ to 5.91$)$ \\
\hline
\end{tabular}

${ }^{*} \mathrm{p}<0.05 ;{ }^{* *} \mathrm{p}<0.01 ;{ }^{* * *} \mathrm{p}<0.001$.

FM, factory-made; HR, hand-rolled; RYO, roll-your-own. 
cigarettes, or a combination of the two (ie, FM and RYO). Among FM cigarette smokers, over 90\% stated that the last purchase of cigarettes was of a single cigarette. According to the survey, smokers purchasing single cigarettes seem to be paying a similar price per stick as smokers who purchase an entire pack. The wide prevalence of single cigarette purchases in Zambia could represent a significant barrier to tobacco control, particularly given that there were no significant differences found in per cigarette prices when sold as singles compared with packs. The Zambian government has not forbidden the sale of loose cigarettes in Ntembas (kiosks); this should be a main focus for tobacco regulation.

Although the reported cigarette price varied, smokers in Zambia paid on average ZMW0.50 (US\$0.08) per stick of FM cigarettes. We also found that smokers who paid less than ZMW0.50 per cigarette were more likely to be brand loyal. Given the reported cigarette prices in this survey and prior findings on the affordability of cigarettes in Zambia (Chelwa G. The tobacco story in Zambia: a demand, supply, and tax analysis. Unpublished manuscript, University of Cape Town, Cape Town, Republic of South Africa), cigarette prices may be too low to motivate smokers to quit. According to the $\mathrm{WHO}$, increasing tobacco taxes is the single most cost-effective strategy to reduce the prevalence of tobacco use, especially among youth. ${ }^{18}$ The finding that there is a significant price differential between Peter Stuyvesant and Pall Mall on the one hand, and Sweet Menthol on the other, is largely explained by the fact that Zambia levies the excise tax on tobacco products as an ad valorem tax (Chelwa G. The tobacco story in Zambia: a demand, supply, and tax analysis. Unpublished manuscript, University of Cape Town, Cape Town, Republic of South Africa). This is consistent with prior evidence of greater price variation in countries with ad valorem taxes, ${ }^{19}$ where low price products are made more attractive by increasing the difference between low-priced and highpriced brands. ${ }^{14}$ The WHO recommends specific tobacco excise taxes since these reduce the gap between premium and low-priced alternatives, and limit opportunities for smokers to switch to cheaper alternatives in response to tax increases.

As expected, we found that smokers under the age of 18 were less likely to be brand loyal. Smokers in this age group were also less likely to report choosing a cigarette brand based on taste. It turns out that young smokers are under-represented in this study. Insufficient analytic power among this subgroup may have suppressed significant associations with respect to price and brand choice. In Zambia as in other countries, the youngest age group is the most vulnerable demographic group to marketing efforts by the tobacco companies. It is likely that the increased focus of the tobacco industry on building their market in Africa will lead to higher smoking prevalence in upcoming years. For this reason, it is critical for governments in Zambia and throughout the African Region to protect the youth by increasing the price and taxation of tobacco products, and banning the sale of single cigarettes. ${ }^{20}$

Low-income smokers reported that they were more pricesensitive, whereas smokers with higher income reported other reasons for their brand choice, such as perceived quality and taste. Evidence from other low-income and middle-income countries $^{20}$ shows that taxation is an effective tobacco control tool among low-income smokers. In other countries, RYO cigarette use has been shown to be consistently and significantly associated with low income. ${ }^{21-23}$ Although it cannot be confirmed with cross-sectional analyses, the concurrent use of RYO cigarettes suggests that low-income smokers in Zambia may be substituting them for FM cigarettes, and this serves as a reminder that future policies should not be limited to only FM cigarettes.

In the absence of restrictions on misleading descriptors such as 'light', 'mild' or 'low tar' on cigarette packages, some Zambian smokers are misled to choose a particular brand on the basis that it is less harmful than others. For example, we found perceived harm to be associated with brand choice among high-income smokers. To date, Zambia has not banned the use of false, misleading or deceptive packaging labels, and therefore these findings are not surprising. The FCTC recommends that governments prohibit the display of quantitative or qualitative statements about tobacco constituents and emissions suggesting that one brand is less harmful than another. ${ }^{18}$ The finding that pack design was not significantly associated with brand choice likely stems from the high proportion of smokers who buy singles rather than packs; the importance of pack design may well increase in the future if restrictions are implemented on the sale of singles.

With respect to limitations of this study, the sample size was relatively small, and thus the statistical power for some of the tests was low, especially among subgroups. Furthermore, our results are cross-sectional and cannot be used to assess tobacco control policy impact. It should be noted, however, that the ITC Zambia Project is a longitudinal cohort study, and longitudinal analyses from Zambia will be forthcoming.

\section{What this paper adds}

- This paper reports findings from the first-ever national study of tobacco use in Zambia and its focus on price, brand choice and brand loyalty. It adds to the still-sparse literature on the economics of tobacco use in the African Region.

- Levels of brand loyalty are high in Zambia, despite low income. These findings will help inform public health practitioners on how to tailor their tobacco control interventions to appeal to different demographic groups.

- The findings on price distribution from this study demonstrate that very low prices, coupled with the very high prevalence (over $80 \%$ ) of single cigarette purchases, pose a challenge for tobacco control efforts in the country and provide the foundation for initiatives to increase taxes on tobacco products.

\section{Twitter Follow Grieve Chelwa at @gchelwa}

Acknowledgements The authors would like to acknowledge the ITC Zambia team for its contributions in planning and implementing the ITC Zambia Survey, and the fieldwork team who conducted the interviews.

Contributors RGS and JFT were responsible for conception. All authors contributed to the design of this study. GTF, FG, SCK and ACKQ were involved in the design of the ITC Zambia Survey. RGS and XC were responsible for data analysis reported in this paper. All authors contributed to the interpretation of the findings. All authors contributed to successive drafts. All authors approved the final manuscript.

Funding The ITC Zambia Project is supported by Canadian Institutes of Health Research (115016). Additional support was provided to Geoffrey T. Fong from a Senior Investigator Award from the Ontario Institute for Cancer Research and a Prevention Scientist Award from the Canadian Cancer Society Research Institute.

Competing interests None declared.

Ethics approval The ITC Zambia Survey was cleared for ethics by the Office of Research Ethics Committee at the University of Waterloo, Canada, and the University of Zambia Biomedical Research Ethics Committee.

Provenance and peer review Not commissioned; externally peer reviewed. 


\section{REFERENCES}

1 Murray CJ, Lopez AD. Global mortality, disability, and the contribution of risk factors: Global Burden of Disease Study. Lancet 1997;349:1436-42.

2 Jha P, Chaloupka F. Tobacco control in developing countries. Oxford, UK: Oxford University Press, 2000.

3 Blecher EH, Ross H. Tobacco use in Africa: tobacco control through prevention. Atlanta, GA: American Cancer Society, 2013.

4 Mendez D, Alshanqeety 0 , Warner KE. The potential impact of smoking control policies on future global smoking trends. Tob Control 2013;22:46-51.

5 Pampel F. Tobacco use in sub-Sahara Africa: estimates from the demographic health surveys. Soc Sci Med 2008;66:1772-83.

6 Zulu R, Siziya S, Muula AS, et al. Associations of advertisement-promotion-sponsorship-related factors with current cigarette smoking among in-school adolescents in Zambia. Ann Afr Med 2009;8:229-35.

7 Siziya S, Rudatsikira E, Muula AS. Cigarette smoking among school-going adolescents in Kafue, Zambia. Malawi Med J 2007;19:75-8.

8 Pampel FC. Patterns of tobacco use in the early epidemic stages: Malawi and Zambia, 2000-2002. Am J Public Health 2005;95:1009-15.

9 Blecher $\mathrm{EH}$, van Walbeek CP. An international analysis of cigarette affordability. Tob Control 2004;13:339-46.

10 Blecher $\mathrm{EH}$, van Walbeek CP. Cigarette affordability trends: an update and some methodological comments. Tob Control 2009;18:167-75.

11 Davis RM. The effects of tobacco advertising: brand loyalty, brand switching, or market expansion? Am J Prev Med 1996;12:2-3.

12 DiFranza JR, Eddy JJ, Brown LF, et al. Tobacco acquisition and cigarette brand selection among youth. Tob Control 1994;3:334-8.

13 Cowie GA, Swift E, Borland R, et al. Cigarette brand loyalty in Australia: findings from the ITC four country survey. Tob Control 2013;23:i73-9.
14 World Health Organization. Technical Manual on Tobacco Tax Administration. http:/l www.who.int/tobacco/publications/tax_administration/en/ (accessed Oct 2014).

15 Fong GT, Cummings KM, Borland R, et al. The conceptual framework of the International Tobacco Control (ITC) Policy Evaluation Project. Tob Control 2006;15 (Suppl 3):iii3-11.

16 Thompson ME, Fong GT, Hammond D, et al. Methods of the International Tobacco Control (ITC) Four Country Survey. Tob Control 2006;15(Suppl 3): iii12-18.

17 Heatherton TF, Kozlowski LT, Frecker RC, et al. Measuring the heaviness of smoking: using self-reported time to the first cigarette of the day and number of cigarettes smoked per day. Br J Addict 1989;84:791-9.

18 World Health Organization. WHO Framework Convention on Tobacco Control. Guidelines for implementation. Article 5.3; Article 8; Articles 9 and 10; Article 11; Article 12; Article 13; Article 14. http://www.who.int/fctc/protocol/guidelines/ adopted/guidel_2011/index.html (accessed 20 May 2014).

19 Liber AC, Ross $\mathrm{H}$, Ratanachena $\mathrm{S}$, et al. Cigarette price level and variation in five Southeast Asian countries. Tob Control 2015;24:e2.

20 Chaloupka FJ, Yurekli A, Fong GT. Tobacco taxes as a tobacco control strategy. Tob Control 2012;21:172-80.

21 Young $\mathrm{D}$, Yong $\mathrm{HH}$, Borland $\mathrm{R}$, et al. Trends in roll-your-own smoking: findings from the ITC four-country survey (2002-2008). J Environ Public Health 2012;2012:406283.

22 Young D, Wilson N, Borland R, et al. Prevalence, correlates of, and reasons for using roll-your-own tobacco in a high RYO use country: findings from the ITC New Zealand survey. Nicotine Tob Res 2010;12:1089-98.

23 Young $\mathrm{D}$, Yong $\mathrm{HH}$, Borland $\mathrm{R}$, et al. Prevalence and correlates of roll-your-own smoking in Thailand and Malaysia: findings from the ITC-South East Asia Survey. Nicotine Tob Res 2008;10:907-15. 